\title{
Effect of electronic patient record use on mortality in End Stage Renal Disease, a model chronic disease: retrospective analysis of 9 years of prospectively collected data Victor E Pollak*1 and Jonathan A Lorch ${ }^{2}$
}

Address: ${ }^{1}$ MIQS Inc., 2100 Central Avenue, Suite 201, Boulder, Colorado 80301, USA and ${ }^{2}$ The Rogosin Institute, 505 East 70 th Street, New York, New York 10021, USA

Email: Victor E Pollak* - vpollak@miqs.com; Jonathan A Lorch - lorchj@mail.rockefeller.edu

* Corresponding author

Published: 28 November 2007

BMC Medical Informatics and Decision Making 2007, 7:38 doi:10.1/86/1472-6947-7-38
Received: 14 June 2007

Accepted: 28 November 2007

This article is available from: http://www.biomedcentral.com/l472-6947/7/38

(C) 2007 Pollak and Lorch; licensee BioMed Central Ltd.

This is an Open Access article distributed under the terms of the Creative Commons Attribution License (http://creativecommons.org/licenses/by/2.0), which permits unrestricted use, distribution, and reproduction in any medium, provided the original work is properly cited.

\begin{abstract}
Background: In chronic disease, health information technology promises but has yet to demonstrate improved outcomes and decreased costs. The main aim of the study was to determine the effects on mortality and cost of an electronic patient record used in daily patient care in a model chronic disease, End Stage Renal Disease, treated by chronic maintenance hemodialysis. Dialysis treatment is highly regulated, and near uniform in treatment modalities and drugs used.
\end{abstract}

Methods: The particular electronic patient record, patient-centered and extensively coded, was used first in patient care in 3 dialysis units in New York, NY in 1998, 1999, and 2000. All data were stored "live"; none were archived. By December 3I, 2006, the patients had been treated by maintenance hemodialysis for a total of 3924 years. A retrospective analysis was made using query tools embedded in the software. The United States Renal Data System dialysis population served as controls. In all there were 1790 patients, with many underlying primary diseases and multiple comorbid conditions affecting many organ systems. Year by year mortality, hospital admissions, and staffing were analyzed, and the data were compared with national data compiled by the United States Renal Data System.

Results: Analyzed by calendar year after electronic patient record implementation, mortality decreased strikingly. In years 3-9 mortality was lower than in years $1-2$ by $23 \%, 48 \%$, and $34 \%$ in the 3 units, and was $37 \%, 37 \%$, and $35 \%$ less than that reported by the United States Renal Data System. Clinical staffing was $25 \%$ fewer per 100 patients than the national average, thereby lowering costs.

Conclusion: To our knowledge, this is the first demonstration that an electronic patient record, albeit of particular design, can have a favorable effect on outcomes and cost in chronic disease. That the population studied has many underlying diseases affecting all organ systems suggests that the electronic patient record design may enable application to many fields of medical practice.

\section{Background}

Care of chronic disease patients now predominates in medical practice, and accounts for $>75 \%$ of US $\$ 2.1$ trillion medical care costs [1]. Health information technol- 
ogy is believed essential in improving outcomes and decreasing costs $[2,3]$. Although an integrated electronic medical record, performance measures, and active performance monitoring has been associated with improved quality measures [4-6], hopes for effects on healthcare quality, efficiency, and costs have yet to be realized. One recent systematic review concluded that the evidence was sparse [7], another found little evidence that computerized clinical decision support has effected patient outcomes [8]. We found no literature on effects of electronic medical records on mortality in any chronic disease.

Over 30 years ago Fries concluded that in chronic disease: "a major failure of the traditional chart is its inability to indicate adequately complex temporal relationships between clinical, laboratory, and therapeutic events [9]." To address these complex temporal relationships, paper spreadsheets were used to manage clinical, laboratory, histological, and therapeutic details sequentially in renal involvement in systemic lupus erythematosus [10]. This approach was expanded to develop a new comprehensive patient-centered paper record to facilitate understanding of systemic and renal manifestations of diseases. After extensive testing it was converted to electronic form [11]. Discrete medical practice details for diseases affecting multiple organ systems were transformed into coded data, enabling rearrangement of data elements to facilitate clinical practice and observations over many years.

End Stage Renal Disease (ESRD) is complex, costly, and affects more than 500,000 patients in the United States [12]. As a model to test effects of this comprehensive, coded and analyzable, electronic patient-centered record (EPR) in chronic disease, ESRD has unique advantages. First, it is highly regulated, with frequent routine and ad hoc State and Federal oversight; treatment adequacy markers must be reported. Second, to start dialysis treatment, patients must meet mandated criteria. Third, treatments, devices, and drugs used are largely standardized. Fourth, dialysis procedures are also largely standardized and, for the most part, operator independent. ESRD often results from primary disease conditions such as diabetes mellitus, HIV/AIDS, multiple myeloma, systemic lupus erythematosus, arteriosclerosis, and hypertension; comorbid conditions affecting many organ systems are universal. Each patient requires lifetime care, receives $140-156$ treatments and accumulates up to $11,600-21,000$ individual data items yearly [13], is cared for in many locations by caregivers from several disciplines. Mandatory reporting ensures that the United States Renal Data System provides a national database and mortality standard with which to compare results. Moreover, $68-70 \%$ of US patients are treated in dialysis units owned by 5 (since recent mergers, 3) large dialysis "chains" [12]; each deploys an electronic medical record [14-17].
We here test the hypothesis that "Successful management and treatment of the patient and the important individual manifestations of a chronic disease require complex feedback systems that relate therapeutic interventions to clinical and laboratory information relevant to multi-organ systems over prolonged periods" [11]. We analyzed retrospectively data collected during patient care from 1998 onward using the EPR, enhanced continually since 1976 [13,18-21]. This study EPR was the test instrument. USRDS mortality data provided contemporaneous controls [12]. Favorable effects on mortality and cost were observed on ESRD patients treated by chronic maintenance hemodialysis (HD) for a total of 3,924 years over a 9-year period.

\section{Methods \\ The setting}

The study was done in 3 dialysis units managed by The Rogosin Institute (New York, NY), affiliated with New York Presbyterian Hospital and Weill Medical College of Cornell University. All provide treatment by in-center chronic HD. Unit A also trains and treats patients by peritoneal dialysis, home HD, and nocturnal self-HD. Eight full-time salaried Rogosin Institute staff nephrologists, who also care for renal and transplant patients, teach, and do clinical research, and 2 nurse practitioners care for patients in Unit A. In Unit B, there are 1 to 2 Rogosin nephrologists, 2 to 5 in private practice, and 1 nurse practitioner. In Unit $\mathrm{C}$, the 3 nephrologists are in private practice.

\section{Participants}

The patients were all 1790 patients treated by chronic maintenance HD from 91 days after ESRD start.

\section{Design of the study}

The electronic patient record (Disease Manager Plus ${ }^{\mathrm{TM}}$, MIQS ${ }^{\circledast}$ Inc, Boulder, CO) employs a relational database (Sybase ${ }^{\circledast}$ Adaptive Server Enterprise, Sybase, Inc., Dublin, $\mathrm{CA}$ ), running on a server computer (Sun ${ }^{\circledast}$ Microsystems, Santa Clara, CA). It is accessed using a custom toolset (4D, Inc., San Jose, CA) from client personal computers in dialysis units, renal and transplantation practice, physician offices, hospital, and home. All clinical, administrative, and financial information is immediately accessible at all times on patients ever entered into the database. It serves all kidney disease care, including dialysis and transplantation. Subject to security considerations, lifetime patient data relevant to pertinent caregiver needs are accessed whenever and wherever needed. The security ensures confidentiality for clinical and financial information and for integrated electronic mail. Laboratory test results, radiology reports, pathology reports, and dialysis machine data download automatically into the database via MIQSdesigned electronic interfaces. Dialysis machine data ena- 
ble on-line chair-side and remote real-time monitoring including home nocturnal HD [21].

Coded data elements include diagnoses, procedures, symptoms, signs, medications, allergies, and hospitalizations. Patient-specific ICD-9-CM codes record reason(s) medications are prescribed and patients admitted to hospital. Notes are charted in free text or using templates. Advance directives, living will, do not resuscitate, treatment consent, and other documents are stored in the database and readily accessible. HD treatment screens record all details. HD orders and medications to be given during HD automatically populate treatment screen fields.

To provide clinically useful point-of-care reports embedded query tools are incorporated to organize data quickly in any way desired over any time period, to make knowledge available about individual patients, and groups. Reports that can be updated and organized at the pointof-care are user-designed to facilitate clinical decisions based on timely, complete, relevant, patient-specific, time-oriented data.

The electronic starting point for patient encounters displays all relevant historical information including reports, medications, allergies, and patient-specific and rules based alerts and reminders. Encounters, tailored to specific functions such as HD, peritoneal dialysis, chronic kidney disease, and transplantation facilitate data entry and communication with others, e.g., referring physicians. Individual patient reports accessible on encounter and HD treatment screens include contemporaneous medications, comprehensive lifetime lists of diagnoses, surgical procedures, diagnostic procedures, allergies, adverse drug reactions, immunizations, and hospitalizations (Figures 1 and 2). Others display data over time in spreadsheet format from domains including signs, symptoms, medications, laboratory tests, HD orders and treatments, diagnoses, procedures, and hospitalizations (Figure 3).

Patient treatment groups, a special software functionality, define patients receiving treatment courses by in-center HD, other dialysis modalities, kidney and pancreas transplants. An in-center HD group is defined by dates of first and last HD in a treatment course. Reason the course ended is charted from a coded list that includes patient expired, recovered renal function, transferred to another dialysis unit, transferred to another group, e.g., kidney transplant.

\section{Data Analysis}

Reports that incorporate information from multiple information domains were used for data analysis on patient groups. An integrated patient selection query tool enabled selection of cohorts for inclusion in reports. Among selection criteria were demographic elements, locations, alive or expired within a defined time range, presence or absence of $\leq 3$ patient groups and $\leq 3$ ICD coded diseases and procedures.

The Treatment History with Adjusted Dates report enabled much analysis. It adjusted dates automatically to first and last days of the chosen period, calculated days in the group, and displayed why the group ended. For the present analysis it was modified by adding age (at treatment history start), ethnicity, gender, ESRD date (first ever treatment by dialysis or transplantation), date of death, primary cause of ESRD. ESRD vintage was calculated as (Start date of dialysis in the period of study - ESRD date).

The report was generated using the patient selection query tool to select the pertinent HD cohort, Unit A, B, or C, individual calendar year or full 6-9 year spans. Days in the group were summed and average age calculated. Saved as an ASCII file, it was imported for further analysis into Microsoft ${ }^{\circledast}$ Excel $^{\circledast}$ or SAS $^{\circledast}$ JMP $^{\text {тм }}$.

USRDS reports data only from the $91^{\text {st }}$ day after start of the first dialysis treatment [12]. To enable comparable analyses, data were sorted first by (Start date - ESRD date), and second by treatment group days. Patients starting dialysis within $<91$ days and with $<91$ dialysis treatment days were excluded. Those starting dialysis within 91 days of ESRD date were included if treated for $>90$ days; treatment group days were reduced by days prior to the $91^{\text {st }}$, as in USRDS.

The reason treatment was discontinued was examined, using the following conventions:

- Kidney transplants: Patients were deemed alive at the end of the prior dialysis course.

- Deaths: Date treatment was discontinued because patient expired was checked with date of death recorded under patient demographics. Known death within 30 days of transfer to hospital, nursing home, hospice or another dialysis unit was ascribed to the previous modality.

- Transfers to other units for continuing dialysis care: The database was searched for site of future dialysis care, and latest recorded patient-caregiver contact. Time from transfer to last documented contact was calculated. Patients documented alive $\geq 6$ months after transfer were treated for analysis as alive at relevant study year-end. Patients with no such information available were considered "lost to follow up" 


\section{CONDITIONS RELATED TO KIDNEY AND URINARY TRACT BENIGN ESSENTIAL HYPERTENSION \\ HYPERTENSIVE CHRONIC KIDNEY DISEASE, BENIGN, WITH \\ END STAGE RENAL DISEASE \\ SECONDARY HYPERPARATHYROIDISM (OF RENAL ORIGIN)}

\section{CONDITIONS AND PROCEDURES RELATED TO DIALYSIS}

ARTERIOVENOSTOMY FOR RENAL DIALYSIS

left forearm fistula

ARTERIOVENOSTOMY FOR RENAL DIALYSIS

Irtt upper amm graft

OTHER COMPLICATIONS DUE TO RENAL DIALYSIS DEVICE, clotted graft

REVISION OF ARTERIOVENOUS SHUNT FOR RENAL DIALYSIS thrombectomy left upper am w/ angioplasty at brachial vein outflow. venous anastamosis, and at venous limb of the graft

REVISION OF ARTERIOVENOUS SHUNT FOR RENAL DIALYSIS left upper am C-shaped synthetic grafft followup of thrombectomy see scanned report

OTHER COMPLICATIONS DUE TO RENAL DIALYSIS DEVICE. clotting of acces

REVISION OF ARTERIOVENOUS SHUNT FOR RENAL DIALYSIS Thrombectomy followed by multiple angioplasties and a stent across the venous anastomosis of this thrombosed graft bic of severe resistant lesion at the venous anastomosis. See scanned report

OTHER COMPLICATIONS DUE TO RENAL DIALYSIS DEVICE. clotted graft

REVISION OF ARTERIOVENOUS SHUNT FOR RENAL DIALYSIS declotting of graft see scanned report

OTHER COMPLICATIONS DUE TO RENAL DIALYSIS DEVICE, clotted graft

REVISION OF ARTERIOVENOUS SHUNT FOR RENAL DIALYSIS thrombosed upper am dialysis access graft. -see scanned report

REMOVAL OF ARTERIOVENOUS SHUNT FOR RENAL DIALYSIS infected part of access removed and vectra graft taken out.

REVISION OF ARTERIOVENOUS SHUNT FOR RENAL DIALYSIS original fistula left forearm $A V$ fistula

REPAIR OF ARTERIOVENOUS FISTULA

REVISION OF ARTERIOVENOUS SHUNT FOR RENAL DIALYSIS recannulization of an immature fistula. see scanned report

REMOVAL OF ARTERIOVENOUS SHUNT FOR RENAL DIALYSIS perm cath pulled at Dr's office

REVISION OF ARTERIOVENOUS SHUNT FOR RENAL DIALYSIS L.I. Amer Access

REVISION OF ARTERIOVENOUS SHUNT FOR RENAL DIALYSIS AV Fistula evaluation, see scanned report
$\underline{I C D}$

$401.1 \quad 1997$

$403.11 \quad 1998$

$585.6 \quad 08 / 16 / 1999$

$588.81 \quad 11 / 03 / 2004$

$39.27 \quad 07 / 1999 \quad 09 / 1999$

$39.27 \quad 09 / 1999$

$996.73 \quad 09 / 12 / 2004 \quad 09 / 15 / 2004$

$39.42 \quad 09 / 13 / 2004 \quad 09 / 13 / 2004$

$39.42 \quad 09 / 22 / 2004 \quad 09 / 22 / 2004$

$996.73 \quad 09 / 23 / 2004 \quad 10 / 2004$

$39.42 \quad 09 / 24 / 2004 \quad 09 / 24 / 2004$

$996.73 \quad 01 / 05 / 2005 \quad 01 / 06 / 2005$

$39.42 \quad 01 / 06 / 2005 \quad 01 / 06 / 2005$

$996.73 \quad 02 / 10 / 2005 \quad 02 / 12 / 2005$

$39.42 \quad 08 / 13 / 2005 \quad 08 / 13 / 2005$

$39.43 \quad 08 / 31 / 2005 \quad 08 / 31 / 2005$

$39.4210 / 10 / 2005$

$39.53 \quad 10 / 11 / 2005 \quad 10 / 11 / 2005$

$39.42 \quad 11 / 09 / 2005 \quad 11 / 09 / 2005$

$39.43 \quad 12 / 12 / 2005 \quad 12 / 12 / 2006$

$39.42 \quad 12 / 29 / 2005$

$39.42 \quad 12 / 29 / 2006 \quad 12 / 29 / 2006$

Figure I

"Bird's eye view" of the first part of the lifetime history of a patient treated by in-center HD since August I999. Disease conditions related to the kidney and urinary tract, and disease conditions and procedures related to dialysis are displayed. Organized for a dialysis patient, they are displayed chronologically under the corresponding headings. ICD-9-CM codes and descriptors, in upper case, are used to display the diagnoses and procedures. Brief comments, which had been added to the entry screens, appear in lower case beneath the ICD coded descriptors where they provide clinical color for the codes, 


\begin{tabular}{|c|c|c|c|}
\hline & $\underline{I C D}$ & Start date & End date \\
\hline \multicolumn{4}{|l|}{ OTHER CONDITIONS } \\
\hline TOBACCO USE DISORDER & 305.1 & 1975 & 2001 \\
\hline ANEMIA IN CHRONIC KIDNEY DISEASE & 285.21 & $08 / 1999$ & \\
\hline REFLUX ESOPHAGITIS & 530.11 & 2000 & \\
\hline $\begin{array}{l}\text { HEMORRHAGE OF GASTROINTESTINAL TRACT, UNSPECIFIED } \\
\text { black tamy stool and fall in BP }\end{array}$ & 578.9 & $11 / 2000$ & \\
\hline OTHER SPECIFIED IRON DEFICIENCY ANEMIAS & 280.8 & $11 / 2003$ & \\
\hline MIXED HYPERLIPIDEMIA & 272.2 & $04 / 2004$ & \\
\hline $\begin{array}{l}\text { OTHER DISORDERS OF VITREOUS } \\
\text { staph infection }\end{array}$ & 379.29 & $02 / 2006$ & $03 / 2006$ \\
\hline $\begin{array}{l}\text { STAPHYLOCOCCUS AUREUS SEPTICEMIA } \\
\text { no obvious source }\end{array}$ & 038.11 & $02 / 2006$ & $03 / 2006$ \\
\hline $\begin{array}{l}\text { ACUTE AND SUBACUTE BACTERIAL ENDOCARDITIS } \\
\text { vegeatiobn by echo }\end{array}$ & 421.0 & $03 / 2006$ & $03 / 2006$ \\
\hline RECENT RETINAL DETACHMENT, TOTAL OR SUBTOTAL & 361.05 & $03 / 06 / 2006$ & $03 / 09 / 2006$ \\
\hline \multicolumn{4}{|l|}{ ALLERGIC REACTIONS } \\
\hline \multicolumn{4}{|l|}{ ALLERGY: None stated } \\
\hline \multicolumn{4}{|l|}{$\underline{\text { SURGICAL PROCEDURES }}$} \\
\hline $\begin{array}{l}\text { COLONOSCOPY } \\
\text { for GI Bleed - neg }\end{array}$ & 45.23 & $11 / 2000$ & $11 / 2000$ \\
\hline $\begin{array}{l}\text { ESOPHAGOGASTRODUODENOSCOPY (EGD) WITH CLOSED BIOPSY } \\
\text { for GI Bleed - neg }\end{array}$ & 45.16 & $11 / 2000$ & $11 / 2000$ \\
\hline \multicolumn{4}{|l|}{ DIAGNOSTIC PROCEDURES } \\
\hline BONE SCAN & 92.14 & $07 / 23 / 2003$ & $07 / 23 / 2003$ \\
\hline \multicolumn{4}{|l|}{ No evidence of osteoporosis. See text report and test image. } \\
\hline ELECTROMYOGRAPHY & 93.08 & $07 / 31 / 2003$ & $07 / 31 / 2003$ \\
\hline \multicolumn{4}{|c|}{$\begin{array}{l}\text { Nerve Conduction: Abnomal electrical study with evidence of a predominantly motor polyneuropathy } \\
\text { with demyelinating features. The leg is affected to a greater extent than the am. See scanned } \\
\text { report. }\end{array}$} \\
\hline \multicolumn{4}{|l|}{ See scanned report. } \\
\hline \multicolumn{4}{|l|}{ see scanned report. } \\
\hline \multicolumn{3}{|l|}{ see scanned report. } & $12 / 31 / 2003$ \\
\hline $\begin{array}{l}\text { OTHER MICROSCOPIC EXAMINATION OF SPECIMEN FROM UPPER } \\
\text { GASTROINTESTINAL TRACT AND OF VOMITUS }\end{array}$ & 90.89 & $02 / 12 / 2004$ & $02 / 12 / 2004$ \\
\hline \multicolumn{4}{|l|}{ see scanned report. } \\
\hline DIAGNOSTIC ULTRASOUND OF ABDOMEN AND RETROPERITONEUM & 88.76 & $07 / 21 / 2004$ & $07 / 21 / 2004$ \\
\hline $\begin{array}{l}\text { DIAGNOSTIC ULTRASOUND OF HEART } \\
\text { see scanned report }\end{array}$ & 88.72 & $02 / 03 / 2005$ & $02 / 03 / 2005$ \\
\hline OTHER CHEST X-RAY & 87.49 & $02 / 25 / 2006$ & $02 / 25 / 2006$ \\
\hline OTHER DIAGNOSTIC ULTRASOUND & 88.79 & $02 / 26 / 2006$ & $02 / 26 / 2006$ \\
\hline OTHER CHEST X-RAY & 87.49 & $02 / 27 / 2006$ & $02 / 27 / 2006$ \\
\hline OTHER DIAGNOSTIC ULTRASOUND & 88.79 & $03 / 04 / 2006$ & $03 / 04 / 2006$ \\
\hline DIAGNOSTIC ULTRASOUND OF HEART & 88.72 & $05 / 01 / 2006$ & $05 / 01 / 2006$ \\
\hline \multicolumn{4}{|l|}{$\begin{array}{l}\text { compared to prior study, mitral vegetation is not see: posterior leaflet } \\
\text { shows focal thickening. See scanned report. }\end{array}$} \\
\hline \multicolumn{4}{|l|}{ VACCINATIONS } \\
\hline Pneumovax $230.5 \mathrm{ml}$ & & $05 / 01 / 2006$ & $05 / 2 / 2006$ \\
\hline hepatitis $\mathrm{B}$ vaccine (recombinant) $40 \mathrm{mcg}$ & & $05 / 01 / 2006$ & $05 / 02 / 2006$ \\
\hline influenza virus vaccine (split virus) $0.5 \mathrm{ml}$ & & $10 / 24 / 2006$ & $10 / 25 / 2006$ \\
\hline \multicolumn{4}{|l|}{ HOSPITALIZATIONS } \\
\hline HOSPITALIZATION & & $01 / 06 / 2004$ & $01,07 / 2004$ \\
\hline
\end{tabular}

\section{Figure 2}

"Bird's eye view" of the second part of the lifetime history of a patient treated by in-center HD since August I999. Disease conditions other than those related to kidney and urinary tract, allergic reactions, surgical procedures, diagnostic procedures, vaccinations, and hospitalizations are displayed. Reports of this type in which data are organized relevant to the needs of other fields such as cardiovascular disease, hematology, social work, etc are also immediately available. 
$08 / 02 / 2006 \quad 07 / 05 / 2006 \quad 06 / 07 / 2006 \quad 05 / 03 / 2006 \quad 04 / 05 / 2006 \quad 03 / 01 / 2006$

\begin{tabular}{|c|c|c|c|c|c|c|}
\hline & & & & & $04 / 05 / 2006$ & $03 / 01 / 2006$ \\
\hline \multicolumn{7}{|c|}{ (1) } \\
\hline Pre-HD & 80 & 82.6 & 85 & 84.3 & 84.4 & 86.1 \\
\hline Post-HD & 79.9 & 80.5 & 81.2 & 81.6 & 81.6 & 81.5 \\
\hline Target weight ( $\mathrm{kg}$ ) & 80 & 81 & 81.5 & 81.5 & 81.5 & 81.5 \\
\hline [Target - Post-HD] weight & 0.0 & -1.6 & -3.5 & -2.8 & -2.9 & -4.6 \\
\hline \multicolumn{7}{|l|}{ Blood pressure (sitting) } \\
\hline Pre-HD & $138 / 74$ & $144 / 91$ & $193 / 107$ & $138 / 91$ & $166 / 98$ & $193 / 110$ \\
\hline Post-HD & $129 / 63$ & & $161 / 86$ & $140 / 77$ & $161 / 82$ & $140 / 73$ \\
\hline Target BP & $130 / 80$ & $130 / 80$ & $130 / 80$ & $130 / 80$ & $130 / 80$ & $130 / 80$ \\
\hline [Target - Post-HD] BP & $1 / 17$ & & $-31 i-6$ & $-10 / 3$ & $-31 /-2$ & $-10 \pi$ \\
\hline \multicolumn{7}{|l|}{ Dialysis Treatment } \\
\hline Ordered dialyzer & FOpt160 & FOpt160 & FOpt160 & FOpt160 & FOpt160 & FOpt160 \\
\hline Average blood flow & 479 & 501 & & 499 & & 455 \\
\hline \multicolumn{7}{|l|}{ Treatment time (min) } \\
\hline Delivered & 240 & 240 & 240 & 240 & 240 & 240 \\
\hline Ordered & 240 & 240 & 240 & 240 & 240 & 240 \\
\hline \multicolumn{7}{|l|}{ Blood processed (liters) } \\
\hline Delivered & 106.55 & 106.68 & 108.2 & 107.49 & 106.8 & 100.64 \\
\hline Target & 120 & 120 & 120 & 120 & 120 & 120 \\
\hline [Target - Delivered] liters & 13.4 & 13.3 & 11.8 & 12.5 & 13.2 & 19.3 \\
\hline Serum Urea (mmol/L) [pre] & 11.07 & 16.78 & 11.42 & 13.92 & 12.50 & 16.78 \\
\hline Serum Urea (mmol/) [post] & 3.57 & 4.64 & 2.85 & 3.92 & 3.21 & 4.64 \\
\hline $\operatorname{URR}(\%)$ & 67.7 & 72.3 & 74.9 & 71.7 & 74.2 & 72.3 \\
\hline \multicolumn{7}{|l|}{ KTN } \\
\hline Delivered & 1.23 & 1.48 & 1.66 & 1.48 & 1.59 & 1.57 \\
\hline Target & 1.60 & 1.60 & 1.60 & 1.60 & 1.60 & 1.60 \\
\hline [Target - Delivered] KTN & 0.36 & 0.11 & -0.06 & 0.11 & 0.00 & 0.02 \\
\hline חPCR & 0.32 & 0.42 & 0.35 & 0.38 & 0.36 & 0.43 \\
\hline \multicolumn{7}{|l|}{ Calcium,Phosphorus } \\
\hline Serum Ca (mmoli) & 2.35 & 2.25 & 2.12 & 2.20 & 2.15 & 2.30 \\
\hline Serum P (mmolin) & 1.06 & 1.00 & 0.80 & 0.71 & 0.77 & 1.16 \\
\hline $\mathrm{Ca} * \mathrm{P}$ & 2.50 & 2.25 & 1.71 & 1.56 & 1.66 & 2.67 \\
\hline Serum Alk Phos (uI) & 135 & 101 & 99 & 111 & 128 & 56 \\
\hline PTH Intact (ng L) & 161.3 & 244.7 & 180.2 & 117.3 & 172.4 & 225.5 \\
\hline Hectorol / doxercalciferol & 1 mcg tiw & 1 mcg tiw & $1 \mathrm{mcg}$ tiw & 2 mcg tiw & 2 mcg tiw & 2 mcg tiw \\
\hline \multicolumn{7}{|l|}{ Anemia / Hernatology } \\
\hline Hematocrit (proportion of 1) & 0.43 & 0.39 & 0.35 & 0.35 & 0.38 & 0.34 \\
\hline Hemoglobin (g $\mathrm{L}$ ) & 139 & 129 & 118 & 116 & 123 & 120 \\
\hline TSAT $(\%)$ & 38.3 & 56.3 & 42.0 & 50.0 & 51.8 & 47.7 \\
\hline SerumFerritin (ugh) & & 89 & & & 177 & \\
\hline Epogen / epoietin & 3300 tiw & 3300 tiw & 3300 tiw & 2200 tiw & 2200 tiw & 2200 tiw \\
\hline Platelets $\left(10^{\wedge} 9 \mathrm{~L}\right)$ & 188 & 164 & 160 & 170 & 165 & 175 \\
\hline \multicolumn{7}{|l|}{ Electrolytes / Nutrition } \\
\hline Serum Albumin ( $g / L$ ) & 45 & 43 & 40 & 42 & 43 & 42 \\
\hline Serum K (mEqL) & 4.4 & 5.2 & 4.6 & 4.8 & 4.9 & 4.6 \\
\hline Serum Glucose (mmoll) & 5.99 & 6.93 & 5.77 & 5.82 & 5.93 & 4.77 \\
\hline
\end{tabular}

Figure 3

Report designed to enable caregivers to review the effects of treatment. It displays relevant "core" data of one patient for the present and the previous five months. Under headers weight, blood pressure, and dialysis treatment (with sub headers treatment time, blood processed, and $\mathrm{Kt} / \mathrm{V}$ ) the data derive from HD orders, HD treatments, and laboratory test results. They are arranged to provide feedback between orders for and treatments delivered. Relevant lab test results and medications are also displayed to enable review of common problems under headers calcium/phosphorus, anemia/hematology, and electrolytes/ nutrition. Reports with an expanded relevant data set are immediately available for more detailed review of each of these problems. 


\section{Calculation of Mortality}

Mortality per 1000 patient years was calculated for each individual study unit in each calendar year, as is done by USRDS, by dividing the number of deaths in each individual year by the total time in years that the patients were treated by HD in that calendar year, and multiplying by 1000 .

\section{Data Verification}

Analyses were made on several occasions. Dubious or missing values were checked and corrected as necessary in the EPR. Many coded values were missing because data had been charted as text only; coded values were entered from physician text notes. For final analysis, reports were run by individual calendar years and the entire 7-9 year period.

\section{Study Approval}

The study was approved by the Institutional Review Board of Weill Medical College of Cornell University.

\section{Results}

\section{Patients}

The subjects of this report are 1790 patients treated by chronic maintenance hemodialysis from 91 days after ESRD start. Their mean age of $59.2 \pm 16.16$ (SD) years was 2.1 years older than that of USRDS (Table 1 ). There were more females, fewer Whites, more Blacks, more other/ unknown racial groups, and more Hispanics. The proportion with ESRD due to diabetes mellitus type I was lower, whereas that due to diabetes mellitus type II, hypertension, glomerulonephritis, and polycystic kidney disease reflected national data (Table 2 ).

Patients in the 3 Units differed in several characteristics. They were younger in Unit A than in B and C (Table 3). In Unit $C$ more started treatment within 91 days of ESRD than in $A$ and $B$, fewer within $>2$ years. In Unit A there were more with diabetes mellitus type I, glomerulonephritis, polycystic kidney disease, and fewer with diabetes

Table I: Selected patient demographic data, at first HD treatment, between January I I998 and December 3I, 2006

\begin{tabular}{|c|c|c|}
\hline & All Units & USRDS* \\
\hline Number of patients & 1790 & 709,259 \\
\hline $\begin{array}{l}\text { Mean age at start of first HD } \\
\text { treatment during the study period } \\
\text { (years) }\end{array}$ & 59.2 & 57.1 \\
\hline Gender (male:female) (\%) & $52.9: 47.1$ & $54.7: 45.3$ \\
\hline $\begin{array}{l}\text { Race (White: Black: Other/Unknown) } \\
(\%)\end{array}$ & $42.4: 36.4: 21.2$ & $63.3: 28.5: 8.2$ \\
\hline Hispanic (\%) & 17.4 & 12.5 \\
\hline
\end{tabular}

*USRDS data are prevalence of all ESRD patients for the years 1998-2005 combined.
Table 2: Primary disease causing ESRD

\begin{tabular}{lcc}
\hline & All Units (\%) & USRDS* (\%) \\
\hline Diabetes mellitus Type I (juvenile) & 4.0 & 6.3 \\
Diabetes mellitus Type II (adult onset & 32.4 & 29.5 \\
or unspecified) & & \\
Glomerulonephritis & 14.6 & 15.7 \\
Hypertension & 24.2 & 22.3 \\
Systemic lupus erythematosus & 1.9 & 1.9 \\
Polycystic kidney disease & 4.2 & 4.2 \\
AlDS nephropathy & 1.9 & 0.6 \\
Neoplasm (renal and urological), & 1.6 & 0.9 \\
myeloma, amyloidosis & & \\
Hydronephrosis, obstruction, infection & 2.9 & 4.6
\end{tabular}

*USRDS data are prevalence of all ESRD patients for the years 1998-2005 combined.

mellitus type II (Table 4). There were fewer with hypertension in Unit C.

\section{Mortality}

Over the entire study period, 13 patients recovered sufficient function to discontinue dialysis (Table 5). In Unit A, $12.7 \%$ of patients received a kidney transplant, $7.7 \%$ and 9.1\% respectively in Units B and C. More Unit C patients (19\%) were lost to follow up than A (11\%) and B (8\%) patients. In Units $A, B$, and $C$ mortality was respectively 156,171 , and 173 per 1000 patient years, lower than the 1998-2005 USRDS HD mortality (229-241 per 1000 patient years) [12].

As might be expected when the number of patients in each unit was relatively small, mortality did vary substantially year-to-year (Table 6). Nevertheless, save for year 2001 in Unit A, mortality decreased strikingly in each Unit, from

Table 3: Selected patient demographic data, at first HD treatment, in each dialysis unit

\begin{tabular}{|c|c|c|c|}
\hline & $\begin{array}{c}\text { Unit A } \\
(1998-2006)\end{array}$ & $\begin{array}{c}\text { Unit B } \\
(1999-2006)\end{array}$ & $\begin{array}{c}\text { Unit C } \\
(2000-2006)\end{array}$ \\
\hline Number of patients & 858 & 515 & 417 \\
\hline $\begin{array}{l}\text { Age at start of first } \\
\text { HD treatment during } \\
\text { the study period } \\
\text { (years) }\end{array}$ & 56.9 & 60.4 & 62.5 \\
\hline $\begin{array}{l}\text { Gender } \\
\text { (male: female) (\%) }\end{array}$ & $53.7: 46.3$ & $52.6: 47.4$ & $51.8: 48.2$ \\
\hline $\begin{array}{l}\text { Race (White: Black: } \\
\text { Other/Unknown) (\%) }\end{array}$ & $40.9: 38.2: 20.9$ & $\begin{array}{c}49.1: 23.1: 27 . \\
8\end{array}$ & $37.4: 49.2: 13.6$ \\
\hline Hispanic (\%) & 19.1 & 17.8 & 13.4 \\
\hline $\begin{array}{l}\text { Dialysis vintage } \\
\leq 91 \text { days }(\%)\end{array}$ & 41.2 & 41.9 & 65.0 \\
\hline $\begin{array}{l}\text { Dialysis vintage } \\
>2 \text { years }(\%)\end{array}$ & 40.6 & 33.2 & 17.0 \\
\hline $\begin{array}{l}\text { Dialysis vintage } \\
>5 \text { years }(\%)\end{array}$ & 23.9 & 16.3 & 4.7 \\
\hline
\end{tabular}


Table 4: Primary disease causing ESRD in each dialysis unit

\begin{tabular}{lccc}
\hline & Unit A (\%) & Unit B (\%) & Unit C (\%) \\
\hline Diabetes mellitus Type I & 5.7 & 2.3 & 2.4 \\
Diabetes mellitus Type II & 21.5 & 40.5 & 45.0 \\
Glomerulonephritis & 20.6 & 10.5 & 7.2 \\
Hypertension & 26.1 & 26.2 & 18.0 \\
Systemic lupus erythematosus & 2.2 & 1.4 & 2.1 \\
Polycystic kidney disease & 5.7 & 3.3 & 2.2 \\
AIDS nephropathy & 1.6 & 2.1 & 2.2 \\
Neoplasms, myeloma, & 1.9 & 1.0 & 1.9 \\
amyloidosis & & & \\
Hydronephrosis, obstruction, & 3.5 & 1.8 & 2.9 \\
infection & & & \\
\end{tabular}

2000 onward in Unit A, 2001 onward in B, and 2002 onward in C. Considered by year of EPR deployment, mortality was, with a single exception (Unit A, year 4), lower from year 3 onward.

The effect of year-to-year variation may be expected to be less when the results are recapitulated in periods of two or more successive years. Mortality for years 1-2, 3-4, and 5-9 of EPR deployment is summarized in Figure 4. In Unit A, mortality in years 3-4 was 198 per 1000 years, similar to that in years $1-2$. In years 5-9, mortality was 129 per 1000 years, a reduction of 35\%. In Unit B, mortality was $44 \%$ lower in years 3-4 than in years $1-2$, and $49 \%$ lower in years 5-8. In Unit C mortality was $36 \%$ lower in years 3-4 than in years $1-2$, and $32 \%$ lower in years 5-7. By contrast, the contemporaneous USRDS mortality remained constant around 237 per 1000 years from 1998 to 2003, and decreased slightly to 232 and 229 per 1000 years in 2004 and 2005.

As a test of trend, the mortality data from all 3 Units were then combined and a simple regression analysis of mortality per 1000 years was calculated (Figure 5). This produced a regression of 244.4 - 14.18 per year of study EPR use (adjusted $\mathrm{r}^{2}=0.72, \mathrm{p}=0.0022$ ). Thus, the mortality decreased by 28 per thousand every two years. It cannot be assumed, however, that this trend will continue with more extended use of the study EPR.

USRDS mortality calculations include deaths in hospitals, nursing homes, other dialysis units, and elsewhere. Complete knowledge of patients transferred is not available to individual dialysis units, nor was it for this analysis. Of 351 patients transferred to other units, 113 were documented alive an average of 2.32 years later. As some of the other 238 patients may have died and because death might have been attributed to Unit A, B, or C, mortality was recalculated, assuming that 25\%, (approximating the USRDS $23.7 \%$ ) died by end of the calendar year. So calculated, the difference in mortality between years 3-9 inclusive of electronic patient record deployment and years $1-2$ changed little; it was lower by $17 \%$ in Unit A, $43 \%$ in Unit B, and 26\% in Unit C.

Mortality in years 3-9 inclusive was recalculated for the 3 Units combined assuming that 25\%, 50\%, 75\%, or $100 \%$ of those lost to follow up died by end of the calendar year in which they were transferred (Figure 6). Mortality would have been $31 \%, 26 \%, 20 \%$, and 14\% less than USRDS assuming respectively that $25 \%, 50 \%, 75 \%$, or $100 \%$ of those lost to follow up died.

\section{Hospital Admissions}

Over the entire study period, patients in Units A and B were admitted to hospital an average of 1.24 (range 1.08 to 1.39 ) and 1.32 (range 1.01 to 1.65 ) times per year, i.e., $39 \%$ and $35 \%$ less frequently than the USRDS rate of 2.04 [12]. Patients in Unit C were admitted to hospital 2.97 times per year in years 1-2 of EPR deployment, a rate reduced to 2.01 in years $3-7$.

\section{Staff}

Since 2004 patient and staff counts as of December 31 of each year have been provided in the annual Dialysis Facility report by the ESRD Network of New York. Patients treated by both HD and peritoneal dialysis are included. In 2004 and 2005 clinical staff numbered 14.1, 13.4, and

Table 5: Summary of patient outcomes in each dialysis unit over the 7-9 year period

\begin{tabular}{|c|c|c|c|}
\hline & $\begin{array}{l}\text { Unit A } \\
(1998-2006)\end{array}$ & $\begin{array}{l}\text { Unit B } \\
(1999-2006)\end{array}$ & $\begin{array}{l}\text { Unit C } \\
(2000-2006)\end{array}$ \\
\hline Years of observation & 1926.7 & 1046.2 & 951.0 \\
\hline Recovered renal function & 4 & 3 & 6 \\
\hline Received a kidney transplant & 109 & 40 & 38 \\
\hline $\begin{array}{l}\text { Followed in the database after transfer to peritoneal dialysis, home hemeral } \\
\text { or nocturnal hemodialysis }\end{array}$ & 41 & 3 & 3 \\
\hline Known to be alive after transfer to another dialysis facility & 79 & 22 & 12 \\
\hline Lost to follow up after transfer to another dialysis facility & 102 & 50 & 86 \\
\hline Deaths & 303 & 178 & 164 \\
\hline Deaths per 1000 patient years & 157.3 & 170.1 & 172.5 \\
\hline
\end{tabular}


Table 6: Patients treated, treatment duration, and mortality by calendar year in each dialysis unit. USRDS data are shown for comparison

\begin{tabular}{|c|c|c|c|c|c|c|c|c|c|}
\hline Years & 1998 & 1999 & 2000 & 2001 & 2002 & 2003 & 2004 & 2005 & 2006 \\
\hline \multicolumn{10}{|c|}{ Number of patients treated during each year } \\
\hline Unit A & 279 & 236 & 294 & 295 & 268 & 287 & 313 & 317 & 340 \\
\hline Unit B & NA & 112 & 152 & 157 & 166 & 160 & 167 & 232 & 258 \\
\hline Unit C & NA & NA & 154 & 171 & $17 \mid$ & 180 & 190 & 192 & 193 \\
\hline \multicolumn{10}{|c|}{ Mean age (years) at start of HD treatment in each year } \\
\hline Unit A & 56.9 & 58.7 & 57.3 & 57.2 & 56.1 & 56.0 & 57.3 & 56.7 & 58.2 \\
\hline Unit B & NA & 60.7 & 59.9 & 59.5 & 60.0 & 59.7 & 60.8 & 61.5 & 62.9 \\
\hline Unit C & NA & NA & 62.5 & 63.4 & 64.2 & 61.9 & 61.5 & 62.6 & 62.5 \\
\hline USRDS* & 56.2 & 56.5 & 56.8 & 57.0 & 57.3 & 57.5 & 57.7 & 57.9 & NA \\
\hline \multicolumn{10}{|c|}{ Duration of treatment (years) } \\
\hline Unit A & 193.5 & 173.8 & 221.1 & 208.1 & 207.9 & 219.4 & 232.8 & 235.3 & 244.8 \\
\hline Unit B & NA & 81.0 & 100.2 & 118.6 & 121.6 & 121.9 & 130.6 & 169.3 & 202.9 \\
\hline Unit C & NA & NA & 101.7 & 126.5 & 139.9 & 144.8 & 145.9 & 148.8 & 145.2 \\
\hline \multicolumn{10}{|c|}{ Number of deaths } \\
\hline Unit A & 36 & 35 & 38 & 47 & 29 & 19 & 38 & 34 & 27 \\
\hline Unit B & NA & 25 & 26 & 17 & 21 & 21 & 14 & 27 & 27 \\
\hline Unit C & NA & NA & 27 & 26 & 20 & 22 & 24 & 23 & 22 \\
\hline \multicolumn{10}{|c|}{ Mortality per 1000 patient years } \\
\hline Unit A & 186.1 & 201.4 & 171.8 & 225.8 & 139.4 & 86.2 & 163.2 & 144.5 & 110.8 \\
\hline Unit B & NA & 308.7 & 259.5 & 143.4 & 172.7 & 172.3 & 107.2 & 159.5 & 133.1 \\
\hline Unit C & NA & NA & 265.5 & 205.6 & 142.9 & 151.9 & 164.5 & 154.5 & 151.5 \\
\hline USRDS** & 234 & 241 & 236 & 238 & 237 & 236 & 232 & 229 & NA \\
\hline
\end{tabular}

* USRDS age data are mean age of all prevalent ESRD patients (both dialysis and transplant) in each calendar year.

** USRDS mortality data are for patients treated by HD.

13.5 per 100 patients in Units A, B, and C respectively. In those two years the national average was 18.41 clinical staff per 100 dialysis patients [12]. The data for the three study Units were combined to compare with the USRDS data (Table 7). Clinical staff in the study Units numbered 13.79 per 100 patients, i.e., $25.1 \%$ fewer than the national average. Nurses, patient care technicians, dietitians, and social workers were respectively $29.1 \%, 24.7 \%, 18.6 \%$ and $8.5 \%$ fewer per 100 patients than the USRDS.

\section{Discussion}

Using an earlier EPR version in a single dialysis unit, we reported mortality 25\% below the 1980-1989 national average $[13,22]$. Both EPR software and the national database have been greatly enhanced since. The present study is the first demonstration, to our knowledge, that use of an electronic patient record in any chronic disease practice favorably effects mortality.

Stead wrote recently that improvements from information technology implementation "are difficult to quantify in a practice while changing people's roles, process, and technology at the same time. Most measures have an immediate impact on process whereas many of the expected benefits are in long-term clinical outcomes [8]." We had no a priori knowledge of time needed from initial EPR implementation to development of a measurable outcome, particularly when dependent on many underlying diseases, comorbid factors, care, and other variables. A favorable effect by year 3 seems reasonable because staff had to learn to use and become comfortable with the technology while continuing daily patient care activities, and lower mortality in year 3 is likely to reflect improved qual- 


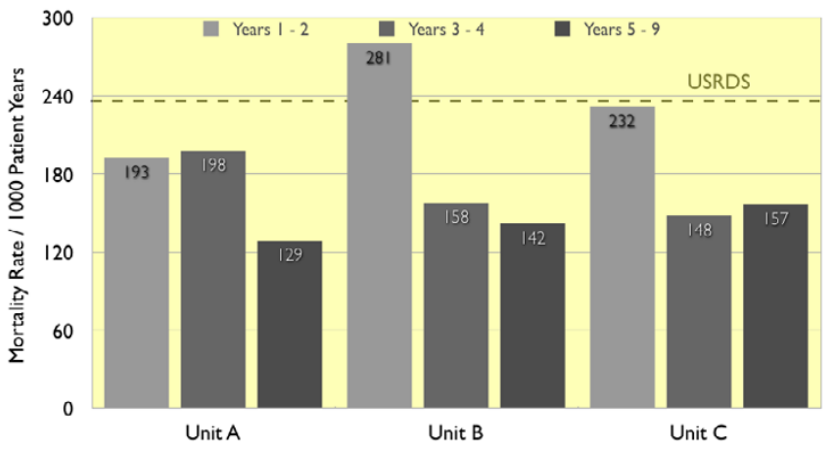

Years of Study Electronic Patient Record Use

Figure 4

Mortality rate, by years of electronic patient record deployment, in dialysis Units $A, B$, and $C$. The mortality rate is compared with that reported by USRDS (horizontal line).

ity of care in year 1 and/or 2 . This was clearly evident in Units B and C by year 3, and in Unit A by year 5 . Lower mortality was observed consistently thereafter for 5 years in Unit A, 6 years in Unit B, and 5 years in Unit C.

That mortality of the study population was less than USRDS might be explained by differences between demographic and comorbid factors of the study and USRDS populations. To test for this possibility we obtained standardized mortality ratios (SMR) generated by the University of Michigan Kidney Epidemiology and Cost Center [23]. Since 2001, SMR has been calculated from a Cox model, adjusting for age, race, ethnicity, gender, diabetes, ESRD duration, patient comorbidities and body mass

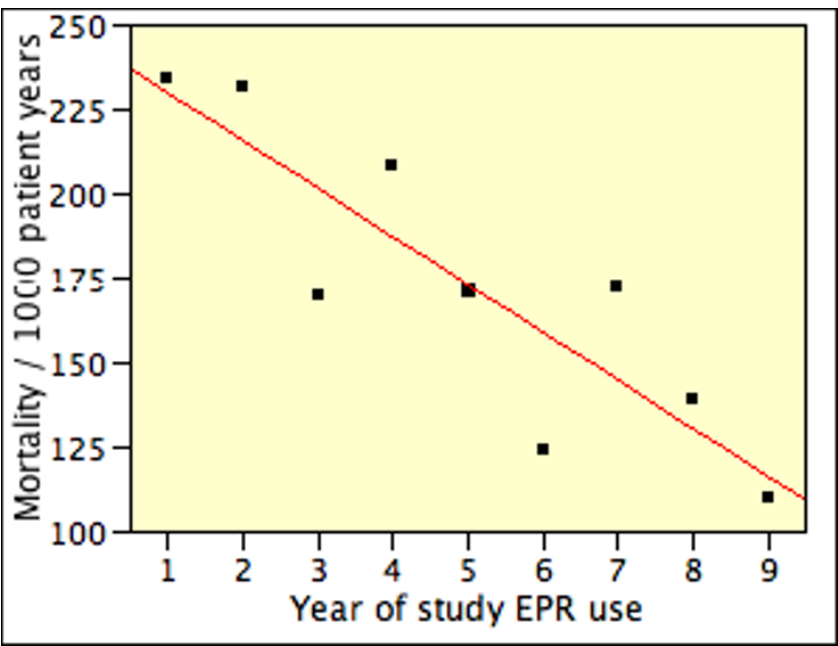

Figure 5

Data from all 3 dialysis units combined were used to analyze regression of mortality per 1000 patient years on years of study electronic patient record (EPR) use.

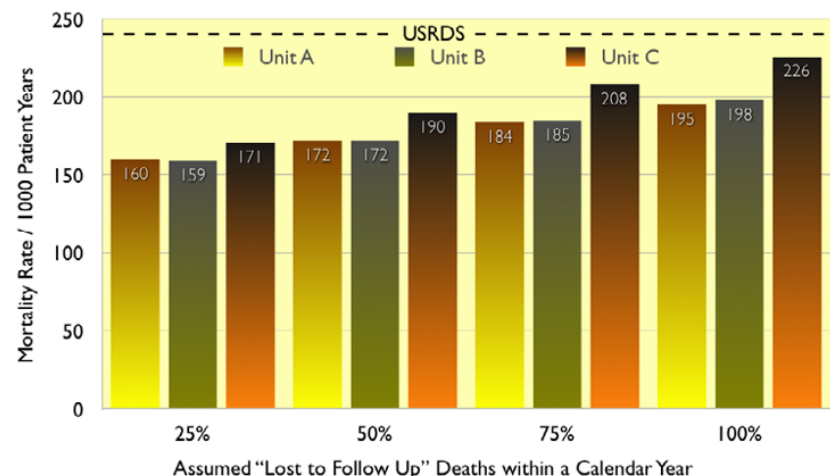

Figure 6

Mortality in years 3-9 combined, with varying assumptions about mortality within a calendar year among patients "lost to follow up".

index at incidence, and population death rates. SMR trends in 2001-2006 were similar to those in our analysis. Compared on a year-by-year basis, SMR and the study patient mortality correlated significantly (adjusted $\mathrm{r}^{2}=$ $0.30, \mathrm{p}=0.011$ ), suggesting that the decreased mortality in 2001-2006 was not due to differences in demographic and comorbid factors of the study and USRDS populations. The demographic and comorbid factors of the population of each Unit, which varied year-to-year almost imperceptibly, cannot explain the lower mortality observed in each Unit. This supports the view that the lower mortality when compared with USRDS was not due simply to a center effect.

We sought to identify other factors such as change in management patterns or dialysis technology that might have contributed to improved outcomes; no obvious ones were found. Increased number and/or professional qualification of patient care staff is one possible explanation; this was not the case. As in an earlier report [13], there was a favorable effect on staff efficiency (Table 7). Compared with years 1-2 hemoglobin and serum albumin, indicators of patient well being, changed little: hemoglobin increased 5\% in years 3-9; serum albumin and serum iron were unchanged. $\mathrm{Kt} / \mathrm{V}$, a widely used index of dialysis adequacy, increased in years $3-9$ by $11 \%, 2 \%$, and $4 \%$ in Units A, B, and $\mathrm{C}$ respectively. Mortality decreased most in Units $\mathrm{B}$ and $\mathrm{C}$, where the change in the index was very small.

\section{Conclusion}

How is it possible that the particular study EPR can have played so important a role? Two properties of the EPR are crucial to understanding: it is patient-centered, and it is extensively coded. 
Table 7: Counts of patients and patient care staff on December 3I, 2004 and December 3 I, 2005

\begin{tabular}{|c|c|c|c|c|}
\hline & \multicolumn{2}{|c|}{ Patient care staff } & \multicolumn{2}{|c|}{ Staff per 100 Patients } \\
\hline & Study Units* & USRDS & Study Units & USRDS \\
\hline \multicolumn{5}{|c|}{ Patients** } \\
\hline & 624 & 326,574 & NA & NA \\
\hline \multicolumn{5}{|c|}{ Staff (Full-time equivalents) $* * * *$} \\
\hline Total patient care staff & 86 & 60,112 & 13.79 & $18.4 \mid$ \\
\hline Nurses (RNs and LPNs) & 34 & 25,109 & 5.45 & 7.69 \\
\hline Patient care technicians & 39.5 & 27,466 & 6.33 & 8.41 \\
\hline Dietitians & 5.75 & 3,675 & 0.92 & 1.13 \\
\hline Social workers & 6.75 & 3,863 & 1.08 & 1.18 \\
\hline
\end{tabular}

* Data are means of counts at the end of years 2004 and 2005.

** Patients treated by hemodialysis and by peritoneal dialysis.

*** Staff who care for hemodialysis and peritoneal dialysis patients. One part-time employee is considered equivalent to 0.5 full-time employee.

The patient-centered study EPR captures, stores, and retrieves on-line and without delay all patient-specific medical data from multiple information domains including diagnoses, procedures, symptoms, signs, medications, orders, test results, and dialysis treatments $[11,18]$. It does so for all venues of care and for care provided by any caregiver, especially important in dialysis where all patients have multiple systemic diseases that need repeated evaluation and treatment by multiple providers over many years at a variety of sites. Unlike disease registries that usually focus on a single disease entity and its assumed complications, the study EPR is a generalized model of medicine that makes no assumption about future co-morbidities, complications, or outcomes in its data model. On the contrary it captures, stores, and retrieves any or all that might occur.

Extensive coding of the study EPR is essential to its utility. The ultimate products of virtually all electronic medical records are notes similar to those in a paper chart; data cannot be added or rearranged to explore varied and unexpected facets of the patient's condition(s), nor can they be viewed over time. The products of the study EPR are reports that contain many domains of data appropriate to a particular disease at any particular moment in time in care of the patient (Figures 1, 2, and 3). Their function is not static documentation of a moment; rather it is to display what has occurred over time, to evaluate and/or change the intervention, and then repeat the process. Essentially the report facilitates continuous quality improvement at the point-of-care [24].

These properties of the study EPR made possible:
(1) Computerized data entry with, and generation of, clinically relevant reports thereby eliminating communication and process errors.

(2) All information needed for skilled clinicians to make best judgments about patient care was always available immediately in clinical reports. Data in reports were complete, from multiple domains, and were viewed sequentially over time (Figure 3 ). We believe that complete, accurate, up-to-date, and focused time-oriented information had a favorable effect on work flow, facilitated understanding of the complex interrelations that effect outcome, enabled clinicians to make best management decisions, and therefore favorably impacted survival.

(3) Aberrant findings in one or a few patients were easily recognized (Figure 7), and their prevalence investigated rapidly $[25,26]$. This knowledge led to development of reports (Figure 8 ) and rules based alerts and reminders (Figure 9) for use in daily clinical practice. Knowledge so derived also enabled survival analysis [27], generated new understanding of a disease [25], decreased symptoms, improved well being $[13,18,22]$, and detected and solved unexpected problems [19].

(4) Development of protocols and their timely updating as new data became available. Recognition of a high prevalence of iron deficiency in anemic epoietin treated dialysis patients led to systematic study, with repeated feedback, of intravenous iron repletion. Unexpected findings included: a very significant rise in serum albumin an excellent outcome marker [28] - and in indirectly measured muscle mass; iron deficiency without iron deficiency anemia; decreased hospital admissions and stay 


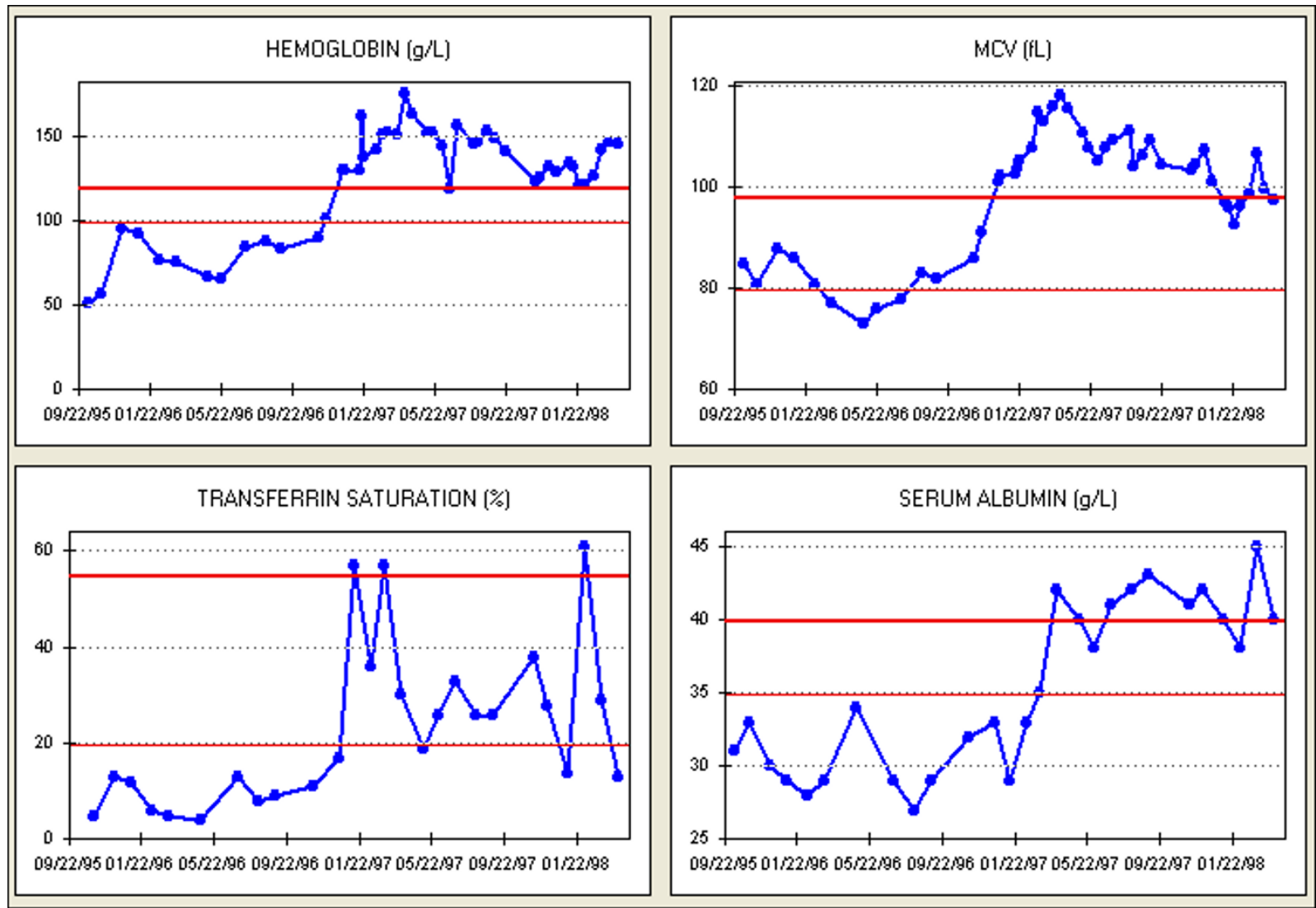

Figure 7

First treated by HD in January 1994, this 39 year old diabetic patient was transferred to a dialysis unit using the study EPR in November 1995. He received intravenous (IV) iron in three I g courses between November 1995 and June I996. A modest improvement in the hemoglobin level occurred, but transferrin saturation (TSAT, an important measure of iron deficiency), mean corpuscular volume (MCV), and serum albumin level (a predictor of mortality) remained low. Recognizing that conventional IV iron replacement had been ineffective, I g courses of IV iron were again given starting in November I996. With appropriate feedback, the courses were repeated whenever measures of iron deficiency were low. Not only was there an excellent hemoglobin response, but two unexpected findings were apparent: MCV increased to well above the normal range, and serum albumin increased to a range predictive of relatively low mortality. These observations were then confirmed in a large patient cohort [26].

[26]. This knowledge was disseminated in the study units when one of us (JAL) joined the Rogosin staff.

A trial of the study EPR with a randomly selected control group has the potential to provide evidence of cause and effect but would be difficult to design and control, and expensive to carry out for the many years needed. The present study compares data between groups and across time periods and uses two national standards, USRDS data [12] and standardized mortality ratio data [23], for contemporaneous controls. Unadjusted and adjusted mortality decreased comparably in 3 practice environments using the study EPR. Nationwide, where $70 \%$ of patients are treated by 3-5 corporations that use a traditional electronic medical record focused on management and billing, there was no concurrent change. With the lim- itations inherent in an observational study, the data provide evidence that benefits in long-term clinical outcomes can be achieved with the study EPR although cause and effect cannot be proven.

The study EPR had a favorable effect on mortality in ESRD patients treated by dialysis. Are similar results possible in other chronic diseases, and with other medical information systems? The challenges are great, as reviewed recently in a study of practice guidelines and quality of care for older patients with multiple comorbid conditions [29]. In 1977 we wrote, "At any time in the course of an illness, the patient may develop one, or many of the universe of symptoms, physical signs, and laboratory abnormalities that occur in clinical medicine as a whole" [11]. The study EPR database, and its integrated query tools, 


\begin{tabular}{|c|c|c|c|c|c|c|c|c|c|c|}
\hline $\begin{array}{l}\text { Account } \\
\text { number }\end{array}$ & date & $\frac{\text { TIBC }}{(\text { umol/L) }}$ & $\frac{\text { Serum }}{\underline{\text { Iron }}}$ & $\frac{\text { ISAT }}{\leq \mathbf{2 0} \%}$ & $\frac{\text { Serum }}{\text { Ferritin }}$ & Hct & $\frac{H b}{(g / L)}$ & $\frac{\text { MCV }}{(\mathrm{fL})}$ & Epoetin & Iron sucrose \\
\hline 75 & $08 / 03 / 2006$ & 51.02 & 8.234 & 16.1 & & 0.494 & 156 & 90.3 & & \\
\hline 87 & $08 / 28 / 2006$ & 36.16 & 5.728 & 15.8 & & 0.355 & 114 & 83.8 & 3,300u 3Nweek & $50 \mathrm{mg}$ once weekly wednesday \\
\hline 87 & $08 / 30 / 2006$ & 34.37 & 5.191 & 15.1 & & 0.366 & 116 & 82.9 & 3,300 u 3Neek & $50 \mathrm{mg}$ once weekly wednesday \\
\hline 92 & $08 / 03 / 2006$ & 49.05 & 5.907 & 12.0 & & 0.574 & 175 & 100 & & $100 \mathrm{mg} 3 \mathrm{Nweek}$ \\
\hline 111 & $08 / 02 / 2006$ & 37.95 & 7.518 & 19.8 & & 0.404 & 134 & 104 & & \\
\hline 168 & $08 / 03 / 2006$ & 36.87 & 6.265 & 17.0 & & 0.385 & 128 & 99.4 & 2200u once weekly thurs & $50 \mathrm{mg}$ once weekly \\
\hline 186 & $08 / 03 / 2006$ & 35.26 & 5.37 & 15.2 & & 0.358 & 110 & 96.6 & 3300 u 3 times weekly & \\
\hline 368 & $08 / 24 / 2006$ & 38.49 & 4.475 & 11.6 & 343 & 0.309 & 97 & 79.8 & & \\
\hline 519 & $08 / 09 / 2006$ & 45.29 & 8.234 & 18.2 & 238 & 0.342 & 106 & 102 & & \\
\hline 1878 & $08 / 02 / 2006$ & 46.18 & 7.339 & 15.9 & & 0.43 & 137 & 95.3 & & $100 \mathrm{ng}$ once weekly thursday \\
\hline 5119 & $08 / 02 / 2006$ & 36.87 & 6.444 & 17.5 & & 0.416 & 131 & 103 & 11,000 u 3week & 50mg once weekly wed \\
\hline 5205 & $08 / 02 / 2006$ & 61.76 & 4.833 & 7.8 & & 0.412 & 133 & 91.6 & & \\
\hline 5664 & $08 / 02 / 2006$ & 37.95 & 7.518 & 19.8 & & 0.351 & 110 & 101 & 12,100 u 3Neek & 100mg once weekly Wed \\
\hline 8092 & $08 / 21 / 2006$ & 62.29 & 9.129 & 14.7 & & 0.324 & 109 & 94.5 & & \\
\hline 10216 & $08 / 02 / 2006$ & 72.32 & 5.728 & 7.9 & & 0.349 & 113 & 90.9 & 4400 u 3 week & $100 \mathrm{ng}$ once weekly every Wednesda \\
\hline 11096 & $08 / 03 / 2006$ & 46 & 9.129 & 19.8 & & 0.379 & 121 & 105 & $4,400 u 3$ times weekly & \\
\hline 11938 & $08 / 44 / 2006$ & 44.75 & 5.37 & 12.0 & 1158.9 & 0.278 & 90 & 90.3 & $12700 \mathrm{u} 3 \mathrm{Neek}$ & somg once weekly wed \\
\hline 11941 & $08 / 02 / 2006$ & 43.32 & 8.055 & 18.6 & & 0.434 & 142 & 88.5 & 2,200 u 3 week & 100mg 3Nweek \\
\hline 12043 & $08 / 21 / 2006$ & 43.14 & 5.907 & 13.7 & 1511 & 0.216 & 68 & 97.8 & 4400 units 3 times weekly & $100 \mathrm{mg} 3$ week $\times 10$ doses \\
\hline 12262 & $08 / 03 / 2006$ & 66.05 & 10.38 & 15.7 & & 0.433 & 131 & 113 & 4,400 u 3 Neek & \\
\hline 12371 & $08 / 02 / 2006$ & 34.91 & 5.907 & 16.9 & & 0.293 & 96 & 103 & 33,000 U 3Meek & \\
\hline 14325 & $08,08 / 2006$ & 32.58 & 5.37 & 16.48 & 174 & 0.308 & 102 & 97 & & \\
\hline 14476 & $08 / 03 / 2006$ & 40.99 & 6.981 & 17.0 & & 0.339 & 106 & 99.5 & $17,600 u 3$ times weekly & \\
\hline 15547 & $08 / 03 / 2006$ & 40.63 & 7.16 & 17.6 & & 0.409 & 125 & 109 & 14,300 u 3Meek & $100 \mathrm{ng}$ once weekly thursday \\
\hline 16067 & $08 / 03 / 2006$ & 37.23 & 5.728 & 15.4 & & 0.366 & 115 & 94.8 & 5,500 u 3 week & \\
\hline 16291 & $08 / 07 / 2006$ & 28.64 & 4.833 & 16.9 & & 0.424 & 135 & 95.4 & 12,100 units 3 times week & $\mathrm{DiC}$ \\
\hline
\end{tabular}

\section{Figure 8}

Iron deficiency and the need for iron replacement treatment are common problems in patients treated by HD. TSAT is an important marker for iron deficiency. This multi-patient report, run each month, displays relevant laboratory data and medications on patients selected for display because the TSAT level was low $(<20 \%$, column 5 ). It enables attention of caregivers to those patients (approximately 60 of 300 ) in whom review of need for iron replacement is particularly desirable.

were designed to enable deployment in many fields of medicine and chronic diseases. If this and other EPR databases are to yield comparable results, we believe it essential that they adhere closely to the dictum that the medical record must be able to indicate complex temporal relationships between clinical, laboratory, and therapeutic events [9], and in both individuals and groups of patients.

\section{Competing interests}

Victor E. Pollak is Founder, Member of the Board of Directors, owner of stock, and full-time employee of MIQS, Inc.

Jonathan A. Lorch is owner of stock of MIQS, Inc.

\section{Authors' contributions}

VEP designed the medical content of the database, and implemented it on paper, 1968-75. In collaboration with software engineers, implemented 3 generations of the EPR starting in 1976, 1982, and 1991 respectively; the third generation is the study EPR used in this manuscript. VEP was responsible for design and implementation of the data analysis. In collaboration with JAL, responsible for writing the manuscript.

JAL implemented the software for clinical, administrative, and billing functions in all clinical facilities of The Rogosin Institute, including the 3 dialysis units that are the subjects of the study. In collaboration with VEP, responsible for writing the manuscript.

Both authors read and approved the final manuscript. 


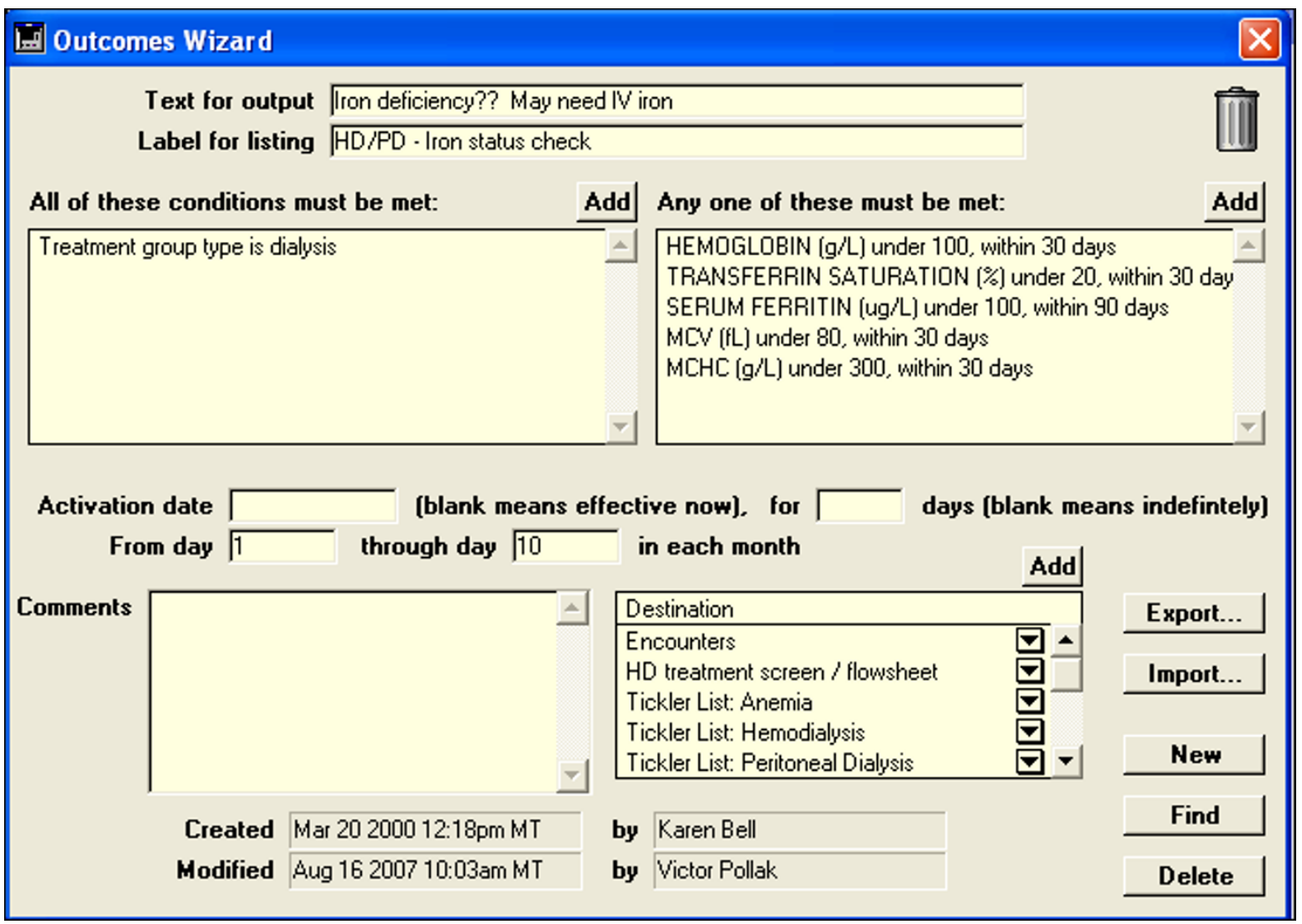

Figure 9

Rules based alert to the possible need for IV iron in patients treated by dialysis. Low values for any one of five laboratory measurements may trigger the alert, which is activated for the period when laboratory measurements are obtained (first 10 days of each month). The alert is directed to appear on encounter screens, HD treatment screens, and in several tickler reports.

\section{Acknowledgements}

The authors wish to thank John P. Flynn whose work in software design over the past 20 years and understanding collaboration with clinicians enabled this study.

We thank C. Ralph Buncher, Sc.D., Department of Epidemiology and Biostatistics, University of Cincinnati, Julien I. E. Hoffman, M.D., Department of Pediatrics, University of California San Francisco, Morris J. Karnovsky, M.D., Department of Pathology, Harvard Medical School, and Robert W. Schrier, M.D., Department of Medicine, University of Colorado who kindly reviewed and commented on early drafts of the manuscript.

Sources of funding and support: None other than salary support for VEP.

\section{References}

I. Heffler S, Smith S, Keehan S, Borger C, Clemens MK, Truffer C: U.S. health spending projections for 2004-20 I 4. Health Aff (Millwood) 2005, Suppl Web Exclusives:W5-74-W5-85.

2. Chasin M, Galvin R: The urgent need to improve health care quality. Institute of Medicine National Roundtable on Health Care Quality. JAMA 1998, 280:1000-1005.

3. Lawrence D: Bridging the Quality Chasm. In Medical Innovation in the Changing Healthcare Marketplace. National Research Council, Institute of Medicine Washington, D.C.: National Academy Press; 2002:65-80.
4. Asch SM, McGlynn EA, Hogan MM, Hayward RA, Shekelle P, Rubenstein L, Keesey J, Adams J, Kerr EA: Comparison of quality of care for patients in the Veterans Health Administration and patients in a national sample. Ann Intern Med 2004, I 41:938-945.

5. Garrido T, Jamieson L, Zhou Y, Wiesenthal A, Liang L: Effect of electronic health records in ambulatory care: retrospective, serial, cross sectional study. Brit Med J 2005, 330:58I-585.

6. Garg AX, Adhikari NK, McDonald H, Rosas-Arellano MP, Devereaux PJ, Beyene J, Sam J, Haynes RB: Effects of computerized clinical decision support systems on practitioner performance and patient outcomes: a systematic review. JAMA 2005, 293: $1223-1238$.

7. Chaudhry BJ, Wang J, Wu S, Maglione M, Mojica W, Roth E, Morton SC, Shekelle PG: Systematic review: impact of health information technology on quality, efficiency, and costs of medical care. Ann Intern Med 2006, I 44:742-752.

8. Stead WW: Rethinking electronic health records to better achieve quality and safety goals. Annu Rev Med 2007, 58:35-47.

9. Fries JF: Time-oriented patient records and a computer data bank. JAMA 1972, 222:1536-I542.

10. Pollak VE, Pirani CL, Schwartz FD: The natural history of the renal manifestations of systemic lupus erythematosus. J Lab Clin Med 1964, 63:537-550.

II. Pollak VE, Buncher CR, Donovan ER: On-line computerized data handling system for treating patients with renal disease. Arch Int Med 1977, 137:446-456.

12. U.S. Renal Data System, USRDS 2006: Annual Data Report: Atlas of End-Stage Renal Disease in the United States. National 
Institutes of Health, National Institute of Diabetes and Digestive and Kidney Diseases, Bethesda, MD; 2007.

13. Pollak VE, Lorch JA: Effective computerized patient record improves patient well-being and financial performance. Dialysis \& Transplantation 2001, 30:807-82I.

14. Teng M, Wolf M, Lowrie E, Ofsthun N, Lazarus JM, Thadhani R: Survival of patients undergoing hemodialysis with paricalcitol or calcitriol therapy. N Engl J Med 2003, 349:446-456.

15. Walters BA, Van Wyck DB: Benchmarking iron dextran sensitivity: reactions requiring resuscitative medication in incident and prevalent patients. Nephrol Dial Transplant 2005, 20:1438-| 442 .

16. Kalantar-Zadeh K, Regidor DL, McAllister CJ, Michael B, Warnock DG: Time-Dependent associations between iron and mortality in hemodialysis patients. J Am Soc Nephrol 2005, I 6:3070-3080.

17. Stidley CA, Hunt WC, Tentori F, Schmidt D, Rohrscheib M, Paine S, Bedrick EJ, Meyer KB, Johnson HK, Zager PG: Changing relationship of blood pressure with mortality over time among hemodialysis patients. J Am Soc Nephrol 2006, I7:5 I3-520.

18. Pollak VE: The computer in medicine: its application to medical practice, quality control, and cost containment. JAMA 1985, 253:62-68.

19. Pollak VE: Computerized medical information system enhances quality assurance: a 10-year experience in chronic maintenance hemodialysis patients. Nephron 1990, 54:109-1 I6.

20. Lorch JA, Pollak VE: Computerized Patient Record in Dialysis Practice. In Replacement of Renal Function by Dialysis 5th edition. Edited by: Winchester JF, Horl WH, Koch KM, Lindsay RM, Ronco C. London, England Kluwer Academic Publishers; 2004:539-53.

21. Lorch JA, Pollak VE, Flynn JP, Solana I: Nocturnal Hemodialysis Treatment at Home: Real-time Monitoring and Data Incorporation into a Longitudinal Patient Database. eHealth International 2003, I:16.

22. Pollak VE, Thornley-Brown D, Kant KS, Pesce A, Deddens JA: A case study of a recent decline in the dialysis fatality rate. Contrib Nephrol 1993, 102:59-72.

23. The University of Michigan Kidney Epidemiology and Cost Center: Guide to the 2006 Dialysis Facility Reports: Overview, Methodology, and Interpretation. 2006:I-25 [http:// www.sph.umich.edu/kecc/usr/facguide.pdf].

24. Rettig RA, Levinsky NG: Examples of ESRD Quality Assurance: Dialysis Clinic Inc., Cincinnati (DCI-C). In Kidney Failure and the Federal Government. Institute of Medicine Washington, D.C. National Academy Press; 1991:309-310.

25. Padilla B, Pollak VE, Pesce A, Kant KS, Gilinsky NH, Deddens JA: Pancreatitis in patients with end stage renal disease. Medicine (Baltimore) 1994, 73:8-20.

26. Pollak VE, Lorch JA, Means RT Jr: Unanticipated favorable effects of correcting iron deficiency in chronic hemodialysis patients. J Investig Med 200I, 49:173-183.

27. Garcia-Garcia G, Deddens JA, D'Achiardi-Rey R, First MR, Samuels SJ, Kant KS, Pollak VE: Results of treatment in patients with end stage renal disease: a multivariate analysis of risk factors and survival in 341 successive patients. Am J Kidney Dis 1985, 5:10-18.

28. Owen WF, Lew NL, Liu Y, Lowrie EG, Lazarus JM: The urea reduction ratio and serum albumin concentration as predictors of mortality in patients undergoing hemodialysis. N Engl J Med 1993, 329:1001-1006.

29. Boyd CM, Darer J, Boult C, Fried LP, Boult L, Wu AW: Clinical practice guidelines and quality of care for older patients with multiple comorbid diseases, implications of pay for performance. JAMA 2005, 294:716-724.

\section{Pre-publication history}

The pre-publication history for this paper can be accessed here:

http://www.biomedcentral.com/1472-6947/7/38/prepub
Publish with Biomed Central and every scientist can read your work free of charge

"BioMed Central will be the most significant development for disseminating the results of biomedical research in our lifetime. "

Sir Paul Nurse, Cancer Research UK

Your research papers will be:

- available free of charge to the entire biomedical community

- peer reviewed and published immediately upon acceptance

- cited in PubMed and archived on PubMed Central

- yours - you keep the copyright
BioMedcentral 